\title{
Equilibrium and Kinetics Studies of Hexavalent Chromium Biosorption by Luffa Cylindrica using Optimised 1,5-Diphenylcarbazide Method
}

\author{
Imane Nouacer ${ }^{* 1}$, Mokhtar Benalia ${ }^{1}$, Ghania Henini ${ }^{2}$, Mebrouk Djedid ${ }^{1}$, Ykhlef Laidani, Chifaa \\ Ad $^{1}$
}

${ }^{1}$ University Amar Telidji-Laghouat, Faculty of Technology, Department Process Engineering, B.P 37G, Laghouat 03000, Algeria

${ }^{2}$ University chlef Faculty of Technology /, Department Process Engineering, Postal address, P.O Box.151. Hay Esslem 02000 Chlef, Algeria

Received: 06/08/2020

Accepted: $23 / 11 / 2020$

Published: 20/03/2021

\begin{abstract}
The Luffa Cylindrica fibers plant have been used as a new biological adsorbent for removal of hexavalent chromium from artificially contaminated aqueous solutions. The experiments took place in the bath mode. The influence of certain parameters on the adsorption of chromuim on the biosorbent, namely the adsorbent-adsorbate contact time, the $\mathrm{pH}$ of the solution and adsorbent dose of hexavalent chromium was determined. The kinetic study has shown that the process of adsorption chromuim on luffa cylindrica is a physical process characterized by its reversibility, by the speed of the establishment of equilibrium. The exploitation of adsorption isotherms using different classical models of Langmuir, Freundlich and Temkin has shown that adsorption can be governed by the Langmuir model. The maximum monolayer biosorption capacity of luffa cylindrica was found to be $5.91 \mathrm{mg}$ of chromium /g of LC. The thermodynamic parameters for the adsorption system were determined at 283,298 and $313^{\circ} \mathrm{K}$. The obtained values showed that the chromium adsorption is a spontaneous and exothermic process. Finally, the Luffa cylindrica has been evaluated by FTIR, SEM and x-ray diffraction in order to determine if the biosorption process modifies its chemical structure.
\end{abstract}

Keywords: Chromium; Biosorption; Isotherms; Thermodynamic; Luffa cylindrica

\section{Introduction}

The production of industrial and urban wastewater, often discharged into the receiving environment (sea, rivers and soils) without prior treatment, causes a degradation of the physicchemical and biological quality of this environment by several pollutants and generates many diseases [1]. As heavy metals whose density exceeds $5 \mathrm{~g} / \mathrm{cm}^{3}$. These are most commonly found in the environment as traces: mercury, lead, cadmium, chromium, copper, arsenic, nickel, zinc, cobalt, manganese [2]. They are characteristic of special chemical properties that make them toxic to humans as well as to living organisms in the animal and plant kingdoms. Chromium is one of the most widely used heavy metals in the industry since it has enough advantages for tanneries, textile, wood processing and agribusiness. Cr (VI) is the most problematic form of chromium since in this form chromium is very toxic and very soluble in water. This solubility gives it high mobility in ecosystems [3]. Wastewater from some industries in Algeria contain chromium at levels well above the standards, such discharges can cause adverse effects on both aquatic fauna and flora. Some studies in Algeria have given an

*Corresponding author: Imane Nouacer, University Amar Telidji-Laghouat, Faculty of Technology, Department Process Engineering, B.P 37G, Laghouat 03000, Algeria. E-mail: i.nouacer@lagh-univ.dz idea about this danger of pollution. It has turned out that the natural water reserves of certain regions near industrial zones, of which chromium forms part of their constituents, are contaminated [4]. Several methods have been used to remove chromuim such as membrane filtration (ultrafiltration, reverse osmosis, nanofiltration, electrodialysis), chemical precipitation, ion exchange and the electrochemical method [5] and adsorption. The use of coal in the adsorption process is also very much in demand. Activated carbon has a high adsorption capacity mainly due to its large specific surface area but this process remains very expensive. The attention was then focused on the use of new adsorbents based on abundant natural materials. Luffa cylindrica, LC, mainly consists of cellulose, hemicelluloses and lignin; of composition $(60 \%, 30 \%$ and $10 \%$ by weight, respectively) [6]. LC has been used as an efficient adsorbent or as a carrier for immobilization of some microalgal cells for the removal of water pollutants [7].

The objective of this study is to verify the possibility of using natural LC as a support for the immobilization of $\mathrm{Cr}$ (VI) ions from the aqueous solution. For this purpose, the various parameters that control the immobilization of $\mathrm{Cr}$ (VI) by the LC (solid mass, $\mathrm{pH}$ solution, contact time and temperature) were optimized, followed by a kinetic and thermodynamic study. The general thrust of this research is to valorize a lignocellulosic waste as a biosorbent of heavy metals. More specifically, the 
present work aims to study, in an optimization perspective, the influence of some key parameters on the biosorption capacity of $\mathrm{Cr}$ (VI) by the fibers of Luffa cylindrica, that is very available and cheap and this from aqueous solutions artificially polluted. A modeling of the adsorption isotherms and a thermodynamic study were also carried out in order to understand the nature of the reaction mechanisms involved during the present biosorption phenomenon.

\section{Material and methods}

\subsection{Preparation of the biosorbent biomass}

The Luffa Cylindrica fibers were manually washed with distilled water and scrubbed with a brush to remove salts, lime scale and sediment from the surface. Subsequently, they were dried in the open air for 24 hours, then in an oven at $40{ }^{\circ} \mathrm{C}$ for 48 hours. The dried leaves were then finely ground (the particle size between 0.5 and $2 \mathrm{~mm}$ ), washed again with distilled water, and then placed in the oven at $80^{\circ} \mathrm{C}$. for 48 hours until their weight become constant and then stored in desiccators.

\subsection{Preparation of the chromium (VI) solution}

A Cr (VI) stock solution was prepared by solubilizing a determined amount of $\mathrm{K}_{2} \mathrm{Cr}_{2} \mathrm{O}_{7}$ in demonized water to obtain a concentration of $100 \mathrm{mg} / \mathrm{L}$. The other concentrations are obtained by successive dilutions. The initial $\mathrm{pH}$ of the solution was adjusted by adding diluted solutions to $0.1 \mathrm{M} \mathrm{HCl}$ or $\mathrm{NaOH}$.

\subsection{Sample Preparation}

The $\mathrm{Cr}$ (VI) elimination tests were carried out batch wise on a magnetic stirrer by contacting a synthetic solution of $\mathrm{Cr}$ (VI) with a constant mass of the adsorbent. The solid / liquid separation of the sample taken is carried out by filtration under vacuum using a membrane having a porosity of $0.45 \mu \mathrm{m}$. For each filtered sample, the $\mathrm{pH}$ and the content of the residual $\mathrm{Cr}$ (VI) were measured. Various tests have been carried out making it possible to examine the influence of certain parameters on the elimination of $\mathrm{Cr}$ (VI) on the adsorbent, such as the stirring time ( 0 to 3 hours) a, the dose of the adsorbent ( 1 to $20 \mathrm{~g} / 1$ ) as well as the treatment $\mathrm{pH}$ (2 to 6 ). The effect of $\mathrm{pH}$ was studied by buffering the synthetic $\mathrm{Cr}$ (VI) solution using the $\mathrm{HCl}(0.1 \mathrm{~N})$ and $\mathrm{NaOH}(0.1 \mathrm{~N})$ solutions during the adsorption test. The removal efficiency of $\mathrm{Cr}(\mathrm{VI})$ is calculated by equation (1):

$R(\%)=\frac{\left(\mathrm{C}_{\mathrm{o}}-\mathrm{C}_{\mathrm{e}}\right) * 100}{\mathrm{C}_{\mathrm{o}}}$

Where $\mathrm{C}_{0}$ and $\mathrm{C}_{\mathrm{e}}$ are the initial and final concentrations of chromium in the solution in $\mathrm{mg} / \mathrm{L}$. The chromium uptake loading capacity $(\mathrm{mg} / \mathrm{g})$ of LC for each concentration of chromium at equilibrium was determined as [8]:

$q_{e}=\frac{\left(\mathrm{C}_{\mathrm{o}-} \mathrm{C}_{\mathrm{e}}\right) \cdot \mathrm{V}}{\mathrm{m}}$

where $\mathrm{Ce}$ is the equilibrium concentrations of the chromium $(\mathrm{mg} / \mathrm{L})$ in solution, $\mathrm{m}$ is the dose of adsorbent $(\mathrm{g} / \mathrm{L})$.

\subsection{Analysis}

The measurement of the non-adsorbed $\mathrm{Cr}$ (VI) concentration was carried out according to the standard colorimetric method [9]. A sample of $1 \mathrm{ml}$ of the solution is taken which is mixed in an acid medium with a complexing agent, 1,5diphenylcarbazide. Thus, a purple-violet complex is formed after 10 minutes and its intensity is measured spectrophotometrically at $540 \mathrm{~nm}$. The Fourier Transform Infrared Spectroscopy, FTIR (IRPrestige-21, Shimadzu, Japan) was used to identify the different chemical functional groups present in the LC. The analysis was carried out using $\mathrm{KBr}$ and the spectral range varying from 400 to $40 \mathrm{~cm}$. X-ray diffraction studies were performed on X-ray diffractometer (Brucker D8 Advance). XRD studies were carried out using $\mathrm{Cu} \mathrm{K} \alpha$ radiation, a Ni-filter and a scintillation counter as a detector at $40 \mathrm{kV}$ and $40 \mathrm{~mA}$ on rotation from $5^{\circ}$ to $60^{\circ}$ at $2 \Theta$ scale. Each sample was finely powdered into small particle size and homogeneously mixed before subjecting to X-ray radiation. The morphology of natural LC was characterized using a scanning electron microscope (SEM) of HIT S2600 N. The powder was deposited on a support $12 \mathrm{~mm}$ in diameter after metallization with platinum.

\section{Results and discussion}

\subsection{Luffa Cylindrica powder characterization 3.1.1 FTIR studies}

An infrared analysis (FTIR) was performed at the raw LC and LC-Chromium. By comparing the FTIR spectra of LC before and after adsorption, there were remarkable shifts in some bands (Table 1). These bands are the function groups of LC participate in chromium biosorption, the comparison of the specters shown in Figure 2 shows. A broad band at $3340 \mathrm{~cm}^{-1}$ corresponding to the elongation of the $\mathrm{OH}$ groups (of shell structure and water), a broad band at $2921 \mathrm{~cm}^{-1}$ relating to the elongation of the group $\mathrm{C}-\mathrm{H}$, a band at $1650 \mathrm{~cm}^{-1}$ which can very probably relate to the $\mathrm{C}=\mathrm{C}$ elongations of olefins (alkenes) and aromatics, very weak bands between $1392-1506 \mathrm{~cm}$ ${ }^{1}$ which are to be put in relation with the $\mathrm{CH}$ deformations in the aliphatic chains and a wide band between $1000 \mathrm{~cm}-1$ characteristic of the deformation in the plane of the aliphatic $\mathrm{CO}$. The resulting bands may result from the presence of cellulose, hemicelluloses and lignin, the major constituents of the shell, as reported by [9], for the Luffa Cylindrica. Note that the previously described bands are more intense after the adsorption of Chromium on the Luffa Cylindrica.

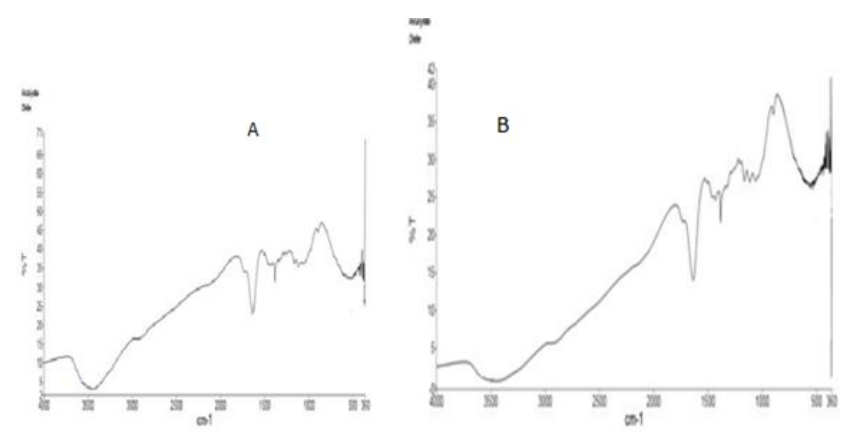

Figure 1: FTIR spectrum of the LC fiber, (a) without adsorbed chromium (VI), (b) with adsorbed chromium

\subsubsection{X-ray diffraction (XRD)}

The XRD pattern of LC and LC-Cr (VI) were shown in Figure 2 (a) and (b). The LC at $2 \theta$ scale showed peaks at $23.34^{\circ}$ and $16.64^{\circ}$ with relative intensities of 1145 and 519 respectively. Similarly, LC- $\mathrm{Cr}(\mathrm{VI})$ showed peaks at $23.07^{\circ}$ and 
$16.81^{\circ}$ with relative intensities of 883.3 and 465 respectively.

Table 1: FTIR spectral characteristics of LuffaCylindrical before and after biosorption of chromium

\begin{tabular}{|c|c|c|c|}
\hline Pics & \multicolumn{2}{|c|}{ Transmission band $\left(\mathrm{cm}^{-1}\right)$} & Assignment \\
\cline { 2 - 3 } FTIR & Before adsorption & After adsorption & Stretching vibration of OH \\
\hline 1 & 3340 & 3326 & Aliphatic C-H group \\
2 & 2921 & 2923 & C=C \\
3 & 1650 & 2348 & C-O \\
4 & 1000 & 1100 & \\
\hline
\end{tabular}

The percentage crystallinity $(\mathrm{Xc} \%)$ and crystallinity index (C.I.) was calculated as follow [10] and [11]:

$\mathrm{Xc} \%=\left\{\frac{\mathrm{Ic}}{\mathrm{Ic}+\mathrm{Ia}}\right\} * 100$

$\mathrm{CI}=\frac{\mathrm{Ic}-\mathrm{Ia}}{\mathrm{Ic}}$

where IC is peak intensity of crystalline phase, IA is peak intensity of amorphous phase.The percentage crystallinity of LC and LC-Cr (VI) fiber was observed as 68.81 and 65.51, while the crystallinity index as 0.54 and 0.47 It was observed that the intensity of the peak in LC- Cr (VI) decreased on adsorption. The decrease in intensity of peak during adsorption indicated decreased crystallinity of LC- $\mathrm{Cr}$ (VI). However; the LC- Cr (VI) showed broadening of the peak after adsorption due to convergence of the fibers toward more disordered system [12]. It has been observed that (Table 2) a slight decreased in percentage crystallinity of the fiber on adsorption copolymerization resulted in increase in randomness or disorder in the crystal lattice of cellulose fiber. This was due to incorporation of chromium on the active sites of backbone during adsorption and fibers became more amorphous and resulted in impaired crystalline structure [13] and [14].

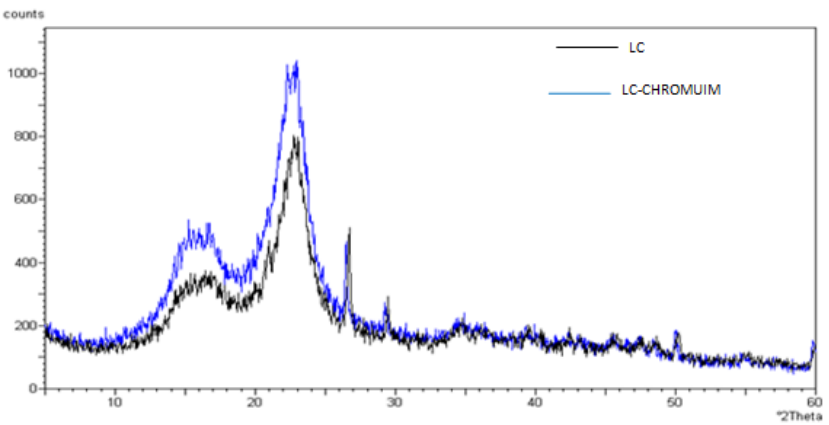

Figure 2: X-ray diffraction spectra of LC and LC loaded with Cr (VI)

Table 2: Percentage crystallinity and crystallization index of Lc and Lc-chromium

\begin{tabular}{|l|c|c|c|c|c|c|}
\hline \multicolumn{1}{|c|}{ Sample } & \multicolumn{2}{|c|}{$2 \theta\left(^{\circ}\right)$} & \multicolumn{2}{c|}{ Intensity } & $\%$ Xc & C.I. \\
\hline & $\begin{array}{c}\text { Crystalline } \\
\text { peak }\end{array}$ & $\begin{array}{c}\text { Amorphous } \\
\text { peak }\end{array}$ & Ic & Ia & & \\
\hline Lc & 23.34 & 16.64 & 1145 & 519 & 68.81 & 0.54 \\
Lc- (Cr(VI) & 23.07 & 16.81 & 883.3 & 465 & 65.51 & 0.47 \\
\hline
\end{tabular}

\subsubsection{Particle's morphology}

Microscopic observation makes it possible to visualize the morphology of the ground material. Optical microscope analysis Figure 3(a,b) and scanning electron microscope observations Figure $4(a, b)$ showed that the beams are a continuation of the vascular system of the stem. The strands or cords that constitute the net are distributed in a very precise manner forming an identical skeleton of one type to another.

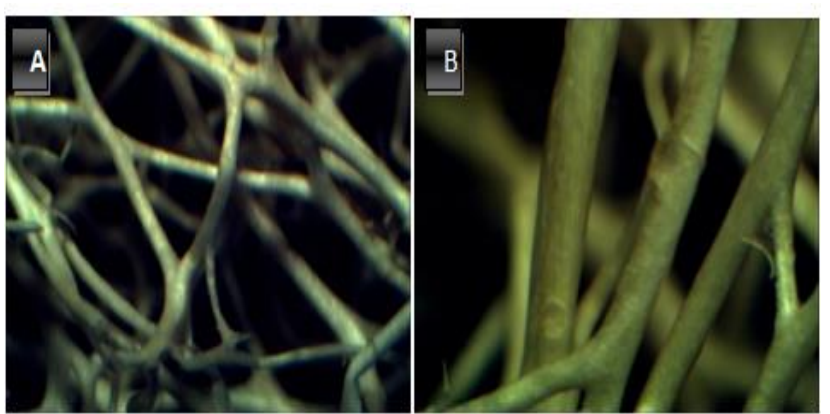

Figure 3: Optical microscope analysis of L.Cylindrica (a) before and (b) after metal Biosorption
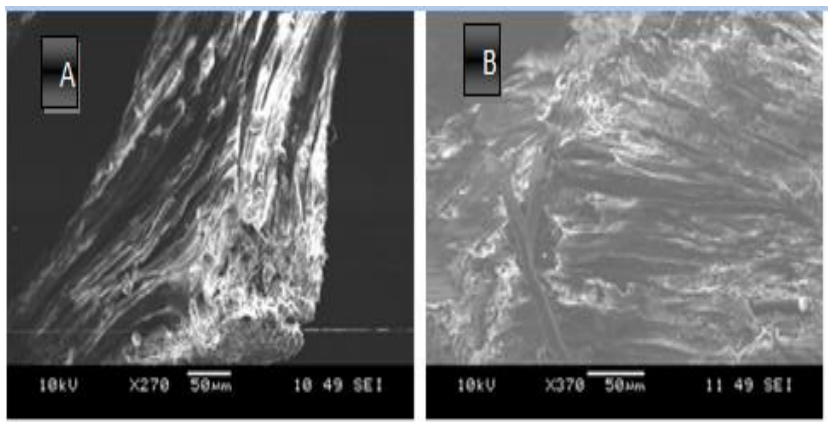

Figure 4: Optical microscope analysis of L.Cylindrica (a) before and (b) after metal Biosorption

\subsection{Influence of contact time}

The effect of contact time on the $\mathrm{Cr}(\mathrm{VI})$ removal rate was studied over a range of 10 to $180 \mathrm{~min}$ with an initial concentration $50 \mathrm{mg} . \mathrm{L}^{-1}$, a dose of biosorbent $20 \mathrm{~g} \mathrm{~L}^{-1}$ at $\mathrm{pH} 2$ and at room temperature. The results showed that the elimination rate increases rapidly during the first 40 minutes, then increases slowly to 130 minutes, and then remains almost constant. The results showed that the removal rate of $\mathrm{Cr}$ (VI) was reached at $90 \mathrm{~min}$ with $80 \%$, equivalent. The increase of the elimination rate in the first part could be due to the external mass transfer which is fast. Then the slow increase in chromium removal rate to 130 minutes equilibrium time. This means that there is an internal mass transfer of the adsorbent; this generally corresponds to a diffusion phenomenon in the internal porosity of the adsorbent.

\subsection{Influence of $\mathrm{pH}$}

The initial $\mathrm{pH}$ of the solution is an important parameter that must be considered in any adsorption study. The effect of this factor on the evolution of the adsorption capacity was analyzed over a $\mathrm{pH}$ range from 2 to 6 . The results showed that the 
maximum amount of $\mathrm{Cr}$ (VI) adsorbed occurs at $\mathrm{pH} 2$ with $80 \%$ for an initial concentration of $50 \mathrm{mg} / \mathrm{L}$. The adsorption capacity decreases sharply when the $\mathrm{pH}$ of the solution goes from 2 to 3 , with a rate of adsorption $66 \%$. Beyond this value of $\mathrm{pH}$, the adsorption capacity still decreases, but less significantly, to record its lowest value at $\mathrm{pH}=7$ with $18 \%$. This behavior is explained by the fact that at $\mathrm{pH}=2$, the functional groups present on the surface of the LC particles (the hydroxyl, carboxyl, phosphonate and sulphonate groups) undergo a strong hydronation, which confers on the parietal bio polymers a positive overall charge. On the other hand, the ionic forms of hexavalent chromium which may be present in solution are anionic in nature such as $\mathrm{HCrO}_{4}^{-}, \mathrm{Cr}_{2} \mathrm{O}_{7}^{2-}, \mathrm{Cr}_{3} \mathrm{O}_{10}{ }^{2-}$ and $\mathrm{Cr}_{4} \mathrm{O}_{13}{ }^{2-}$, and this for $\mathrm{pH}$ values ranging from 1.5 to 4 [14]. Thus, the biosorption involved in the present study seems to be mainly due to an electrostatic attraction phenomenon. In addition, the adsorption capacity recorded decreases with increasing $\mathrm{pH}$. Indeed, the higher the $\mathrm{pH}$, the more the solution is concentrated in free hydroxyl (OH-) radicals which are likely to compete with the anionic species of $\mathrm{Cr}$ (VI) on the active adsorption sites available on the surface of LC fibers. The same trend towards the influence of $\mathrm{pH}$ on $\mathrm{Cr}$ (VI) adsorption has also been reported for other biological matrices such as A. sydoni [29] and Rhizopus [30].

\subsection{Influence of the amount of biomass}

Masses of 0.1 to 5 grams of LC were separately contacted with one liter of $50 \mathrm{mg}$ per $100 \mathrm{~m} \mathrm{~L}$ solution of $\mathrm{Cr}$ (VI) at $\mathrm{pH} 2$. The results shows that the amount of chromium adsorbed at equilibrium increased. Significantly in the weight range examined. In addition, it is observed that the maximum retention is obtained for a mass of 20 grams of LC fibers per liter of solution (rate of adsorption $80 \%$ ) and the minimum retention is observed for a mass of 1 grams of LC (rate of adsorption 11\%). The increase in the retention rate of hexavalent chromium as a function of the increase in the biosorbant mass is mainly due to a consequent increase in the number of active sites of adsorption on the surface of the Mediterranean biomass.

\subsection{Biosorption Kinetics}

In order to study the biosorption kinetics of $\mathrm{Cr}$ (VI) on crushed LC fibers, Lagergren's first-order and pseudo-secondorder models were used for correlation with the experimental data. Lagergren's first-order equation [15] reads as follows:

$\log \left(q_{e}-q_{t}\right)=\log q_{e}-K_{I} \cdot t / 2.303$

Or Qe and Qt (in mg / g) are the amounts of Cr (VI) adsorbed at equilibrium and at time $t$ respectively, and $K_{1}\left(\mathrm{~min}^{-1}\right)$ is the constant of the Lagergren model. From the $\log (\mathrm{Qe}-\mathrm{Qt})$ versus $t$ Figure 5 lines obtained for $\mathrm{Cr}(\mathrm{VI})$ biosorption on LC fibers, the $\mathrm{K}_{1}$ constant and the calculated amount of adsorbed $\mathrm{Cr}$ (VI) (Qecal) were determined by slope and intersection at the $y$-axis, respectively (Table 3). It is clear that the Lagergren equation is not applicable in the case of LC retention on the studied medium in the range of the studied concentration. In addition, the low value of the correlation coefficient $\mathrm{R}^{2}$ obtained for this model indicates the poor description of chromium fixation kinetics by LC. The expression of the second-order model is as follows [16]: $\frac{t}{q_{t}}=\frac{1}{k_{2} q_{e}^{2}}+\frac{1}{q_{e}} t$

Or $\mathrm{K}_{2}$ is the constant relative to this model ( $\mathrm{g} / \mathrm{mg} \mathrm{min}$ ). The graphical representation of the variation of the ratio $t / Q$ as a function of $\mathrm{t}$ gives rise to lines Figure 6 from which the theoretical values $\mathrm{K}_{2}$ and Qecal are determined, respectively with the aid of the slopes and disordered at the origin. These values are presented in Table 4 . The correlation coefficients obtained for the pseudo-second order kinetics model turned out to be the most significant when a minimum value of $99.3 \%$ was recorded for chromuim concentrations of 10 and $60 \mathrm{mg} / \mathrm{L}$. Moreover, the Qe values calculated according to the pseudo-second-order model approach in a very coherent way the values determined experimentally. Moreover, in most of the adsorption systems studied, the first-order model and in particular the Lagergren equation badly correlates the experimental values along the entire adsorption period and is rather generally applicable during the first 20 -30 minutes of the adsorption process [15]. The calculated correlation coefficients are closer to unity for the pseudo-second-order kinetic model than for the pseudo-firstorder kinetic model and the same for theoretical adsorption capacities that are closer to those obtained experimentally. This indicates that the experimental results of $\mathrm{Cr}$ (VI) adsorption on LC are well described by the second-order kinetic model.

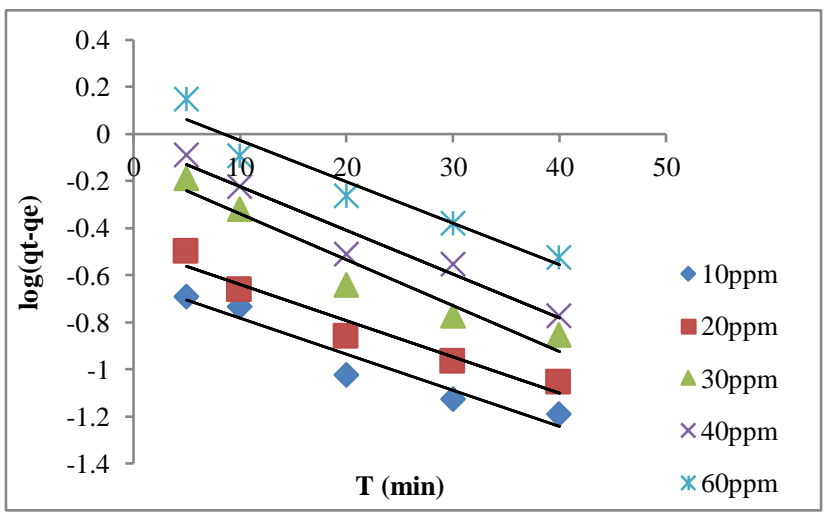

Figure 5:Pseudo-first order kinetic model for $\mathrm{Cr}$ (VI) biosorption onto LC

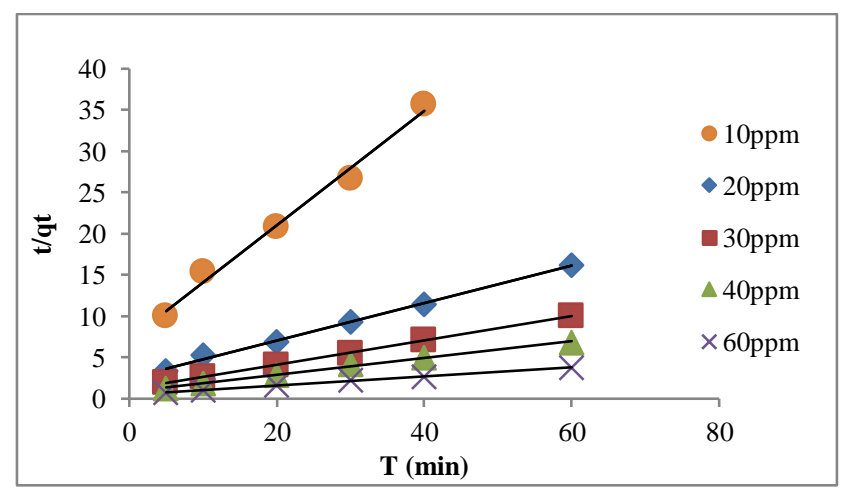

Figure 6:Pseudo-second order kinetic model for Cr (VI) biosorption onto LC 


\subsection{Biosorption isothermes}

The LC binding data are processed using the linear Langmuir, Freundlich, Temkin and Dubinin-Redushkevich equations. The purpose of this linearization is to be able to verify the model according to which the adsorption takes place and to deduce the maximum adsorbed quantities as well as the affinity of the adsorbate for the adsorbent. The concentration of chromuim in solution is monitored as a function of time, for the temperatures 283, 298 and $313 \mathrm{~K}$.

Table 3: Biosorption kinetic model parameters for Cr (VI) by

\begin{tabular}{|c|c|c|c|c|c|c|}
\hline \multirow{4}{*}{$\begin{array}{c}\text { Chromium } \\
\text { conc. }(\mathrm{mg} / \mathrm{L})\end{array}$} & \multicolumn{3}{|c|}{ Pseudo-first order } & \multicolumn{3}{c|}{ Pseudo-second } \\
& \multicolumn{3}{|c|}{} & \multicolumn{3}{c|}{} \\
\cline { 2 - 7 } & $\mathrm{qe}$ & $\mathrm{k}_{1}\left(\mathrm{~min}^{-1}\right)$ & $\mathrm{R}^{2}$ & $\begin{array}{c}\mathrm{qe} \\
(\mathrm{mg} / \mathrm{g})\end{array}$ & $\begin{array}{c}\mathrm{k}_{2}(\mathrm{~g} / \mathrm{mg} \\
\mathrm{min}))\end{array}$ & $\mathrm{R}^{2}$ \\
\hline 10 & 0.23 & 0.034 & 0.929 & 0.354 & 0.306 & 0.997 \\
20 & 0.32 & 0.029 & 0.864 & 0.94 & 0.103 & 0.994 \\
30 & 0.71 & 0.029 & 0.90 & 1.19 & 0.072 & 0.994 \\
40 & 0.92 & 0.036 & 0.95 & 1.92 & 0.052 & 0.993 \\
60 & 1.41 & 0.036 & 0.94 & 2.5 & 0.037 & 0.993 \\
\hline
\end{tabular}

The Langmuir model makes it possible to determine whether a monolayer is adsorbed and whether there has been no interaction between the adsorbed molecules. The Langmuir equation is valid for only one adsorbed monolayer with a well defined number of adsorption sites uniform and energetically identical according to the following relation [19]:

$\frac{C_{e}}{q_{e}}=\frac{q_{\max } K_{l} C_{0}}{1+K_{L} C_{0}}$

The above can be rewritten to the following linear form:

$\frac{C e}{q_{e}}=\frac{1}{K_{L} q_{\max }}+\frac{C e}{q_{\max }}$

where, qe is quantity of substance adsorbed on $1 \mathrm{~g}$ of luffa cylindrica $\left(\mathrm{mg} . \mathrm{g}^{-1}\right)$. Qm is quantity necessary to cover the entire surface with a monolayer of adsorbed substance $\left(\mathrm{mg}^{-\mathrm{g}^{-1}}\right)$. Ce is concentration of chromuim in solution at equilibrium $\left(\mathrm{mg} \mathrm{L}^{-1}\right)$. $\mathrm{K}_{\mathrm{L}}$ is Adsorption energy constant. In order to predict the efficiency of this adsorption process, a dimensionless equilibrium parameter denoted $\mathrm{R}_{\mathrm{L}}$ can be determined by the following equation:

$R_{L}=\frac{1}{\left(1+\mathrm{K}_{\mathrm{L}} \mathrm{C}_{0}\right)}$

where $\mathrm{K}_{\mathrm{L}}$ is the Langmuir constant and $\mathrm{Co}$ is the initial concentration of chromuim ions. The value of separation parameter $R_{L}$ provides important information about the nature of biosorption. The value of $\mathrm{R}_{\mathrm{L}}$ indicated the type of Langmuir isotherm to be irreversible $\left(R_{L}=0\right)$, favorable $\left(0<R_{L}<1\right)$, linear $\left(R_{L}=1\right)$ or unfavorable $\left(R_{L}>1\right)$. The correlation coefficients are high showing in data in figure 7 good linearity the maximum adsorption capacities $\left(\mathrm{q}_{\max }=5.917 \mathrm{mg} / \mathrm{g}\right.$ ) which are very close to those experimentally calculated and thus the values of $R_{L}$ show the validity of the Langmuir model. The $\mathrm{R}_{\mathrm{L}}$ was found to be $0.6-0.146$ for concentration of $10-90 \mathrm{mg} / \mathrm{L}$ of chromium. They are in the range of $0-1$ which indicates the favorable biosorption. These estimated values of $\mathrm{R}_{\mathrm{L}}$, which are less than unity, clearly show favorable adsorption of $\mathrm{Cr}$ (VI) on LC.

The Freundlich model, which gives an indication of the heterogeneity at the surface of the adsorbent [20], was applied to measure the adsorption capacity according to the following relation:

$q_{e}=K_{F} C_{e}^{1 / n}$

where $\mathrm{K}_{\mathrm{F}}$ and $\mathrm{n}$ are Freundlich constants related to adsorption capacity and adsorption intensity. The linear Figure 8 form of the Freundlich equation can be written in a logarithmic form according to the following relation:

$\log \mathrm{q}_{\mathrm{e}}=\log \mathrm{K}_{\mathrm{F}}+\frac{1}{\mathrm{n}} \log \mathrm{C}_{\mathrm{e}}$

The Freundlich constants $\mathrm{K}_{\mathrm{F}}$ and $\mathrm{n}$ has been determined from the isotherms and their values are defined as per in Table 5 for the three temperatures. These constants show their influence on temperature, by the fact that when the temperature increases, the values of $1 / \mathrm{n}$ decrease which implies a decrease in adsorption intensity. We also note that the values of $1 / \mathrm{n}$ are less than unity which indicates favorable adsorption. Since $\mathrm{n}$ lie between 1 and 10, this indicates the physical biosorption of $\mathrm{Cr}$ (VI) on LC.

The Temkin isotherm assumes that the decrease in heat of adsorption is linear and that adsorption is characterized by a uniform distribution of binding energies. BL The linear form of the Temkin isotherm is as follows The linear form of the Temkin isotherm [21] and [22] is as follows:

$\mathrm{q}_{\mathrm{e}}=R T \ln K_{T}+\frac{R T}{b_{T}} \operatorname{In} C_{e}$

$\mathrm{B}_{\mathrm{T}}=\frac{R T}{b_{T}}$

where $b_{\mathrm{T}}$ is the Temkin constant related to heat of biosorption $(\mathrm{J} / \mathrm{mol})$ and $\mathrm{K}_{\mathrm{T}}$ is the Temkin isotherm constant $(\mathrm{L} / \mathrm{g})$. These constants $\mathrm{n}$ were obtained from plotting qe versus $\ln \mathrm{Ce}$. Values of $b_{T}$ and $K_{T}$ are listed in Table 5. The constant Temkin isotherm in Table 5 shows that the heat of adsorption $\left(\mathrm{B}_{\mathrm{T}}\right)$ decreases with increasing temperature, indicating that the adsorption is exothermic. The Dubinin-Redushkevich isotherm (D-R) is applied to determine the nature of the adsorption mechanism based on the theory of potential, assuming that the surface of the adsorbent is heterogeneous. The linear form of the isotherm of (D-R) [23]:

$\ln q_{e}=\operatorname{In} q_{d}-\beta \varepsilon^{2}$

with $\mathrm{q}_{\mathrm{d}}\left(\mathrm{mol} \mathrm{g}^{-1}\right)$ is the theoretical monolayer saturation capacity of the adsorbent and $\varepsilon$ is the Potential of Polanyi is given as follows:

$\varepsilon=R T \ln \left(1+\frac{1}{C_{e}}\right)$ 
Being $\mathrm{R}$ is the gas constant $\left(8.314 \mathrm{~J} . \mathrm{mol}^{-1} \cdot \mathrm{K}^{-1}\right)$ ) and $\mathrm{T}$ is the absolute temperature $(\mathrm{K})$. The isothermal constants of qs and $\mathrm{B}$ (Table4) are obtained from the ordinate and the slope of the Ln qe curve as a function of $\varepsilon^{2}$, respectively. The constant B $\left(\mathrm{mol}^{2}\right.$ $\mathrm{kJ}^{-2}$ ) gives the average free energy, $\mathrm{E}(\mathrm{kJ}$ mol-1) of the adsorption per molecule of the adsorbate when it is transferred to the surface of the solid of the infinite in the solution and can be calculated using the following relationship. From the linear plot of Dubinin-Radushkevich (D-R) model, $\mathrm{q}_{\mathrm{d}}$ was determined to $2.5 \mathrm{mg} / \mathrm{g}$, the mean free energy, $\mathrm{E}=1.18 \mathrm{KJ} / \mathrm{mol}$ indicating a physisorption process. From the data in Table 4, the curves illustrating the isotherms at 283, 298 and 313 K.show that the adsorption follows the Langmuir model, the experimental results can be correlated by the Langmuir equation and the correlation are close to unity.

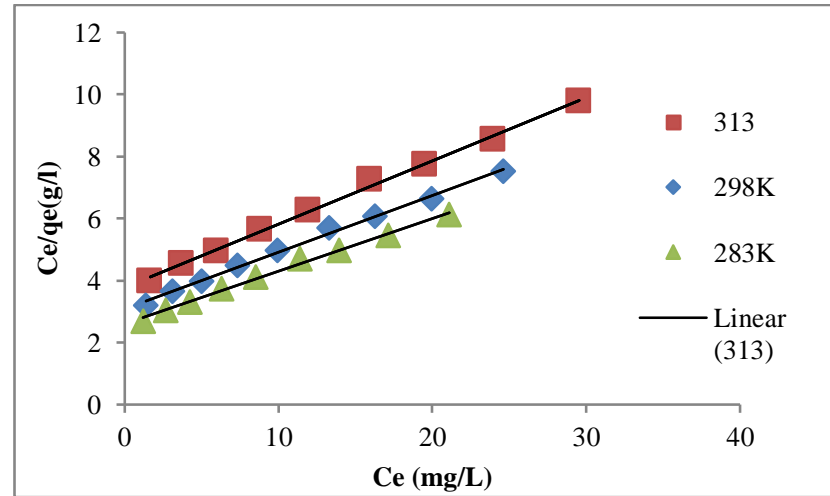

Figure7: Langmuir isotherm for $\mathrm{Cr}(\mathrm{VI})$ biosorption onto $\mathrm{LC}$ at $\mathrm{pH} 2$

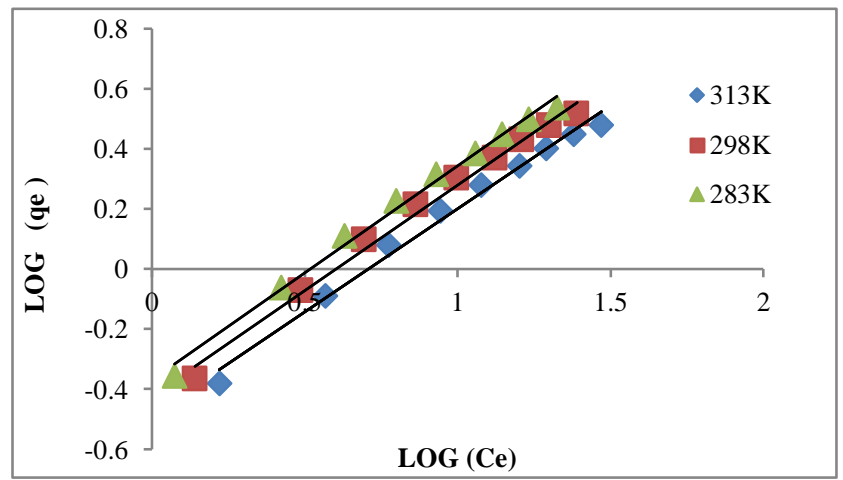

Figure 8: Freundlich isotherm for $\mathrm{Cr}$ (VI)biosorption onto $\mathrm{LC}$ at $\mathrm{pH} 2$

\subsection{Thermodynamic study}

The thermodynamic parameters that shall be taken into consideration in order to qualify the adsorption processes are free energy of Gibbs or free adsorption enthalpy $\Delta \mathrm{G}^{\circ}(\mathrm{kJ} / \mathrm{mol})$ due to the transfer of one mole of solute from the solution to the solid / liquid interface, the adsorption enthalpy; $\Delta \mathrm{H}^{\circ}(\mathrm{kJ} / \mathrm{mol})$ as well as the adsorption entropy; $\Delta \mathrm{S}^{\circ}(\mathrm{J} / \mathrm{mol} / \mathrm{K})$. These quantities were calculated according to the following equations [24] and [25]:

$\Delta G^{0}=-R T \ln K c$
In $K_{C}=\frac{\Delta S^{0}}{R}-\frac{\Delta H^{0}}{R T}$
$\Delta G^{0}=\Delta H^{0}-T \Delta S^{0}$
$K_{c}=\frac{a s}{a e}=\frac{Y s}{Y e}=\frac{C s}{C e}$

$\mathrm{Kc}$ is the adsorption equilibrium constant deduced from the slope of the graph Ln (Qe) as a function of Ce [25], R is the constant of perfect gases and $\mathrm{T}$ is the temperature in Kelvin. The calculations were carried out for a temperature range of 283$313 \mathrm{~K}$. The results are shown in Table 5. The negative value of $\left(\Delta \mathrm{H}^{\circ}\right)$ obtained indicates that the adsorption process of $\mathrm{Cr}$ (VI) is exodothermic in nature [26].

Table 4: Langmuir, Freundlicm, Temkin and D-R constants for $\mathrm{Cr}$ (VI) biosorption by LC

\begin{tabular}{ccccc}
\hline Langmuir & $\mathrm{T}^{\circ}(\mathrm{K})$ & $\mathrm{q}_{\max }(\mathrm{mg} / \mathrm{g})$ & $\mathrm{k}_{\mathrm{l}}(\mathrm{L} / \mathrm{mg})$ & $\mathrm{R}^{2}$ \\
\hline & 283 & 5.917 & 0.0648 & 0.998 \\
& 298 & 5.494 & 0.05891 & 0.998 \\
& 313 & 4.926 & 0.05367 & 0.995 \\
\hline Freundlich & & $\mathrm{K}_{\mathrm{F}}(\mathrm{mg} / \mathrm{l})$ & $1 / \mathrm{n}$ & $\mathrm{R}^{2}$ \\
\hline & 283 & 0.427 & 0.713 & 0.992 \\
& 298 & 0.2377 & 0.703 & 0.989 \\
& 313 & 0.25 & 0.688 & 0.981 \\
\hline Temkin & & $\mathrm{b}_{\mathrm{T}}(\mathrm{J} / \mathrm{ml})$ & $\mathrm{K}_{\mathrm{T}}(\mathrm{L} / \mathrm{g})$ & $\mathrm{R}^{2}$ \\
\hline & 283 & 2770 & 0.9999 & 0.961 \\
& 298 & 2434.98 & 0.9998 & 0.964 \\
\hline D-R & 313 & 2191.73 & 0.9997 & 0.939 \\
\hline & & $\mathrm{q}_{\mathrm{d}}(\mathrm{mg} / \mathrm{g})$ & $\mathrm{B}$ & $\mathrm{R}^{2}$ \\
\hline & 283 & 2.15 & $4 \mathrm{E}-05$ & 0.725 \\
& 298 & 2.27 & $3 \mathrm{E}-05$ & 0.787 \\
& 313 & 2.37 & $3 \mathrm{E}-05$ & 0.728 \\
\hline
\end{tabular}

This confirms the previously discussed results which showed a decreased retention by the elevation of the temperature of the solution. Also, the relative value of $\Delta \mathrm{H}^{\circ}$ confirms the idea that the binding of the chromuim molecules to the luffa cylindrica. Is likely of a physical type. On the other hand, the value of $\left(\Delta \mathrm{S}^{\circ}\right)$ indicates the good affinity of the biosorbent with respect to the $\mathrm{Cr}$ (VI)ions and reflects the increase of the "disorder" factor at the level of the solid interface / solution with some possible structural changes of the adsorbate and the biosorbent during the adsorption process. Moreover, the negative values of $\left(\Delta \mathrm{G}^{\circ}\right)$ show that the adsorption process studied is spontaneous [27].

Table 5: Thermodynamic parameters of $\mathrm{Cr}$ (VI) biosorption onto

\begin{tabular}{llll}
\multicolumn{4}{c}{ LC at different T } \\
\hline$T(\mathrm{~K})$ & $\Delta \mathbf{G}^{\circ}(\mathrm{kJ} / \mathrm{mol})$ & $\Delta \mathbf{H}^{\circ}(\mathrm{kJ} / \mathrm{mol})$ & $\Delta \mathbf{S}^{\circ}(\mathrm{J} / \mathrm{mol} . \mathrm{K})$ \\
\hline 283 & -5.347 & & \\
298 & -5.035 & -11.293 & -0.021 \\
313 & -4.72 & & \\
\hline
\end{tabular}

The negative values of the standard enthalpy $\left(\Delta \mathrm{H}^{\circ}\right)($ table 5$)$ confirm that the adsorption of the chromium molecules at the sites of each adsorbent is of exothermic nature and which is also indicated by the increase of the adsorbed quantity with the decrease of the temperature, and that the molecule / particle interactions are of a physical nature. 


\subsection{Comparison of chromium biosorption with different Biosorbents}

The maximum adsorption capacity $\left(\mathrm{q}_{\max }\right)$ is determined by the Langmuir model at $303 \mathrm{k}$ is compared with other low cost adsorbents (Table 6). These data show that Luffa cylindrica achieves good $\mathrm{Cr}$ (VI) adsorption results. Significant differences in the adsorption capacity of $\mathrm{Cr}$ (VI) ions can be attributed to adsorbent properties such as structure, functional groups and specific surface area. Cr (VI) adsorption on Luffa cylindrica can be considered as an effective and ecologically advantageous alternative.

Table 6: Adsorption capacity of $\mathrm{Cr}$ (IV) on various biosorbents

\begin{tabular}{lll}
\hline Biosorbent & $\mathrm{q}_{\max }$ & references \\
\hline A. sydoni & 1.76 & {$[28]$} \\
Rhizopus & 4.33 & {$[29]$} \\
Water lily & 6.11 & {$[30]$} \\
Water hyacinth & 6.61 & {$[30]$} \\
Green taro & 6.07 & {$[30]$} \\
Mangrove leaves & 6.54 & {$[30]$} \\
Luffa cylindrica & 5.9 & This study \\
\hline
\end{tabular}

\section{Conclusion}

In the present research work, we have studied the biosorption capacity of hexavalent chromium by Luffa Cylindrica fibers that are very available on the Mediterranean coast, L.cylindrica has been demonstrated that the adsorption capacity has equilibrium can be optimized by increasing the amount of biomass, decreasing the temperature, increasing and fixing the $\mathrm{pH}$ of the solution to a value of 2 . Isothermal modeling has shown that the Langmuir model describes satisfactorily the present adsorption process. For thermodynamic parameters, analysis of the results showed that the adsorption of $\mathrm{Cr}$ (VI) on L.cylindrica is a spontaneous, exothermic and favorable phenomenon. On the other hand, the results of the kinetic study of the retention show that the chromium is really in conformity with a kinetics of the second order. This is clearly confirmed by the values of the correlation factors. Taking into account all the results provided by this study, the cheap and fairly available L.cylindrica fibers could be considered as a promising biological material to be used as an effective adsorbent for the removal of chromium. (VI) present in the liquid effluents.

\section{Acknowledgments}

We gratefully acknowledge the university Amar Thelidji Algeria and university of USTHB for assistance and support of this work.

\section{References}

1. Kumar U. Agricultural products and by-products as a low-cost adsorbent for heavy metal removal from water and waste-water: a review. Scientific research and essays. 2006;1(2):33-37.

2. Tutic A , Novakovic S, Lutovac M, Biocanin R, Ketin S , Omerovic N. The Heavy Metals in Agrosystems and Impact on Health and Quality of Life. Macedonian Journal of Medical Sciences. 2015;3(2):345-355.

3. Shanker AK, Cervantes C, Loza-Tavera H, Avudainayagam S. Chromium toxicity in plants. Environment International. 2005;31:39-753.
4. Barkat M, Chegrouche S, Mellah A, Bensmain B, Nibou D, Boufatit M. Application of Algerian Bentonite in the Removal of Cadmium (II) and Chromium (VI) from Aqueous Solutions.Journal of Surface Engi-neered Materials and Advanced Technology. $2014 ; 4,210-226$.

5. Dakiky M, Khamis M, Manassra A, Mer'eb M. Selective adsorption of chromium(VI) in industrial wastewater using low-cost abundantly available adsorbents. Advances in Environmental Research .2002;6(4),533-540.

6. Henini G, Laidani Y, Souahi F, Hanini S. Study of static adsorption system phenol/Luffa cylindrica fiber for industrial treatment of wastewater .Energy Procedia, 2012; 18,395-403.

7. Tanobe VOA, Sydenstricker THD, Munaro M, Amico SC. A comprehensive characterization of chemically treated Brazilian sponge-gourds (Luffa cylindrica). Polym Test .2005; 24(4), 474482.

8. Dang VBH, Doan HD, Dang-Vu T, Lohi A. Equilibrium and kinetics of biosorption of cadmium (II) and copper (II) ions by wheat straw. Bioresource Technology. 2009;100 (1), 211-219.

9. Annija L, David R, Mark B, John C. Chromium Monitoring in Water by Colorimetry Using Optimised 1,5-Diphenylcarbazide Method. International Journal of Environmental Research and Public Health. 2019; 16(10), 1803-1818.

10. Kalia S, Kumar A, Kaith B S. Sunn hemp cellulose graft copolymers polyhydroxybutyrate composites: morphological and mechanical studies . Advanced Material Letters. 2011; 2(1),17-25.

11. Sanghavi B J, Srivastava AK, Adsorptive stripping voltammetric determination of imipramine, trimipramine and desipramine employing titanium dioxide nanoparticles and an Amberlite XAD-2 modified glassy carbon paste electrode.Analyst. 2013; 138 (5), 1395-1404.

12. Sanghavi BJ, Kalambate $P$ K, Karna S P, Srivastava A K Voltammetric determination of sumatriptan based on a graphene/gold nanoparticles/Nafion composite modified glassy carbon electrode. Talanta. 2014; 120, 1-9.

13. Sharma S, Pathania D, Singh P. Preparation, characterization and $\mathrm{Cr}(\mathrm{VI})$ adsorption behavior study of poly(acrylic acid) grafted Ficus carica bast fiber . Advanced Materials Letters. 2013; 4(4), 271-276.

14. Donmez G, Aksu Z. Removal of chromium(VI) from saline wastewaters by. Dunaliella species. Process Biochemistry 2002, 38, 751-762.

15. Lagergren S. Zur theorie der sogenannten adsorption geloster stoffe, Kungliga Svenska Vetenskapsakademiens. S. Handl, 1898; 24(4), 139.

16. Ho YS, Was DAJ, Forster CF. Kinetic Studies of Competitive Heavy Metalby Sphagnum Moss Peat. Environmental Technology. 1996;17(1), 71-77.

17. Mckay G, Ho YS. Pseudo-Second Order Model for Sorption Processes. Process Biochemistry.1999; 34, 451-465.

18. Weber J, Morris JC. Kinetics of Adsorption o $\mathrm{n}$ Carbon from Solution. Journal of the Sanitary Engineering Division..1963; 18, $31-42$.

19. Langmuir I. the adsorption of gases on plane surfaces of glass, mica and platinum. Journal of the American Chemical Society. 1918; 40,1361-1403.

20. Freundlich, H. Adsorption in solution Journal of the American Chemical Society. 1939; 615, 2-28.

21. Aharoni A, Ungarish M. Kinetics of activated chemisorption- part 2. Theoretical models. The Journal of the Chemical Society, Faraday Transactions. 1977; 73,456-464.

22. Boparai HK, Joseph M, O'Carroll DM. Kinetics and thermodynamics of cadmium ion removal by adsorption onto nano zerovalent iron particles. Journal of Hazardous Materials.2011; 186, $458-465$.

23. Hustonn D, Yang RT. Theoretical basis for the DubininRadushkevitch (D-R) adsorption isotherm equation. Adsorption.1997; 3, 189-195. 
24. Al-Anbar ZA, Matouq MAD. Batch adsorption of cadmiumions from aqueous solutions by means of olive cake. Journal of Hazardous Materials. 2008;151, 194-201.

25. Fu QL, Deng YL, Li HS, Liu J, Hua HQ, Chen SW, Sa TM. Equilibrium, kinetic and thermodynamic studies on the adsorption of the toxins of Bacillus thuringiensis subsp. kurstaki by clay minerals. Applied Surface Science. 2009; 255, 4551-4557.

26. Su J, Hong-fu L, Qing-Ping W, Zheng-Miao X, Zuliang C. Equilibrium, kinetic and thermodynamic studies on the adsorption of the toxins of Bacillus thuringiensis subsp. kurstaki by clay minerals. Desalination.2011; 69, 163-169.

27. Canizares P, Carmona M, Baraza O, Delgado A, Rodrigo MA. Adsorption equilibrium of phenol onto chemically modified activated carbon F400. Journal of Hazardous Materials. 2006; 131, $243-248$.

28. Kumar R, Bishnoi NR, Garima KB. Biosorption of chromium(VI) from aqueous solution and electroplating wastewater using fungal biomass. The Chemical Engineering Journal. 2008;135, 202-208.

29. Zafar S, Aqil F, Ahmad I. Metal tolerance and biosorption potential of filamentous fungi isolated from metal contaminated agricultural soil. Bioresource Technology. 2007; 98(13), 2557-2561.

30. Elangovan R, Philip L,Chandraraj K. Biosorption of hexavalent and trivalent chromium by palm flower (Borassus aethiopum) . The Chemical Engineering Journal. 2008 ; 141(1-3), 99-111. 